\title{
Allocating Book Funds: Control or Planning?
}

\begin{abstract}
Allocating book funds in academic libraries originated principally as a device to control powerful departments and prevent them from monopolizing funds. For this reason, present methods for apportioning book budgets often bear little relation to the needs of the collection. Identified or projected book needs are the only valid criteria for determining the use of such funds. Utilizing new budgeting and bibliographic techniques, academic librarians can approach allocation more objectively. This involves a three-step process by which planning and bibliographic research replace control and focus on the actual needs of the collection.
\end{abstract}

\begin{abstract}
A
Llocating bOOK FUnDS by department became common practice in academic libraries toward the end of the nineteenth century. This procedure originated primarily as a control device to prevent monopolization of book funds by particularly active or powerful members of the teaching faculty. Before funds were apportioned, it was not unknown for the teaching faculty to fight over library money. It sometimes became necessary to appoint committees to resolve these disputes. A solution frequently adopted by these committees was to assign a definite sum to each department. In spite of hopes that this would reduce most of the animosity, complaints and challenges continued. In an attempt to defend their decisions, it became almost uniform practice for committees to base allocations on some form of historical data. Although each institution used somewhat different data, several factors were normally con-
\end{abstract}

Mr. Schad is Head Acquisitions Librarian at San Fernando Valley State College, Northridge, California. sidered by most colleges and universities.

Book use as a measure of need was sometimes calculated simply and directly on the basis of circulation statistics by. department. However, because it was difficult to relate circulation to the various departments, other data were more frequently used. For example, allocations were often based on the total number of credit hours registered for each . department, weighted by level (lower division, upper division, graduate), or the courses in each department were weighted on the basis of estimates of library dependence. Other institutions measured book use by the number of faculty members or the number of theses, dissertations, and publications written annually by the students and faculty of each department.

The rate of publication was often taken as an index of budgetary need. Each ${ }^{\text {. }}$ year new publications were reviewed, and relevant titles were assigned to departments. The number of books for each department times the average cost, established a percentage of the total 
budget for each field.

Attempts were often made to consider the needs of the collection. Evidence frequently cited included the number of unfilled requests on hand, expenditures for previous years, each department's percentage of the total collection, the number of new faculty members or new courses, as well as subjective judgments about the strengths and weaknesses of the collection.

As imprecise as these factors were, they did help to make allocation more equitable. Discontent did not subside, however, and it was not until the thirties that the next advance was made. Those years were marked by an increased interest in statistics. Statistical techniques were utilized to devise a number of mathematical formulas for apportioning book funds. They were based on various factors, each of which was assigned a numerical value. The sums of the factors for each department were added, and a percentage of the total became an index for each department's share of the budget. Formulas were more impartial and, in that sense, they did represent a step forward. For this reason, library committees welcomed formulas. However, few librarians exhibited much enthusiasm for them because judgments about which factors were significant and their relative importance were still subjective ones.

Since the development of formulas, procedures for allocating funds have changed very little, and all of them share two major defects: (1) the specific needs of the collection are seldom considered directly, and (2) attitudes of control are still dominant. Each department's share of the budget is calculated from indirect evidence of need, which usually takes the form of a statistical summary of past experience. However, such experience is not necessarily a reliable guide to current or future needs. It is valuable only insofar as it is anal- ogous to the present. Librarians and library committees have misused historical statistics by constructing what seemed to be reasonable budgets, but without analyzing or questioning the data or their relevance to the present. The second defect is equally serious. Because the major concern of library committees was to curb overambitious book selectors and prevent departments from getting more than their share of the budget, attitudes of control rather than the needs of the collection dominated budgetary thinking. Therefore, the process of allocation has not contributed toward effective use of funds, and few librarians have done anything to improve matters. What efforts have been made were normally limited to insuring a degree of budgetary flexibility and library control by establishing funds for the purchase of general books, reference books, periodicals, and perhaps current books, as well as reserve or contingency funds for special needs or purchases. The remaining funds were left to library committees to apportion as they saw fit.

Many librarians recognized these defects and also associated the process of apportioning funds with control of book selection by the teaching faculty. As a result, some rejected the whole idea of allocation. ${ }^{1}$ Nevertheless, allocation can play an important part in the process of collection building. The solution, there- $x$ fore, is not to reject allocation, but to replace traditional methods with an approach that is not dominated by the special interests of the teaching faculty but focuses on the real needs of the collection. Until recently there has been no theoretical framework to assist librarians in developing such an approach. Two developments significantly altered this situation. The first involves the use of , new concepts of budgeting that are gaining increased acceptance not only in business and government, but also in the academic world. In government, tech- 
niques for allocating resources in limited supply during World War II provided a theoretical basis for further applications. In 1961 program budgeting was introduced into the Department of Defense, and in 1965 all departments of the federal government were directed to develop similar budgeting procedures. ${ }^{2}$ Pron gram budgeting contrasts sharply with traditional budgeting, which focuses on objects of expenditures and is marked by attitudes of inertia and control. On the other hand, program budgeting is an objective-oriented, planning process by which available resources are organized to achieve specified goals. Because funds are seldom if ever adequate, financial implications of these goals must be considered. This involves assigning priorities to the component parts of the plan. A time dimension may be required for projects that cannot be completed within a single budgetary period. Programs must be under continuous review in order to clarify needs, and to improve and refine the planning process.

$v$ The second development involves the emergence of bibliographers, or librarians specializing in collection building. Until recently college and university librarians were not sufficiently involved in the affairs of the academic communities they served. Nor were they competent to assess the quality of library resources. Therefore they were not able to contribute significantly toward defining needs or developing collections in their libraries. However, in the forties academic administrators became seriously worried about the seemingly endless financial requirements of libraries and the acquisition of obsolete or little-used material. Librarians began to recognize the importance of planning, and they realized it was necessary to define the amount and character of the literature needed to support educational programs. $^{3}$ At the same time, there was increased pressure on the teaching faculty to publish. This caused them to devote more time to research and less time to activities such as book selection. In addition, library budgets began to grow more rapidly than ever before. All these factors forced academic librarians to assume greater responsibility for collection building. A number of specialists emerged who gradually developed techniques for systematically evaluating and developing collections.

These new budgetary and bibliographic concepts can be effectively combined to produce a method of allocating that reflects the needs of the collection. A three-step process is involved: (1) formulating collecting goals; (2) identifying specific needs; and (3) determining dollar requirements.

The library's responsibility is similar to other schools and departments in that its collection must be designed to support educational objectives in the same way as specific degree programs and course offerings. Because educational goals determine library needs, librarians must be involved in campus-wide planning. They must translate the goals of the academic community into programs for developing library resources. The first step involves establishing the proper level for each area of the collection. Although there are an infinite number of levels of collecting, they may be divided roughly into four different categories: (1) a core collection of books, which all academic libraries should have regardless of their educational programs; (2) a collection to support undergraduate instruction; (3) basic research collections to support graduate programs; and (4) comprehensive research collections to support advanced research.

The appropriate level for each part of the collection can be established only after careful analysis of every significant factor bearing on library needs. Although these may vary from institution 
to institution, they are generally as follows:

1. The nature of the instructional programs. The educational objectives, the type of students being trained, the degree programs, as well as specific course offerings are all basic factors. Instructional methods are related to these, and they are perhaps the single most important determinant of the nature and scope of library use. Programs that emphasize individual learning are heavily dependent on the library, whereas those that utilize the lecture-textbook method often make little or no use of the library.

2. Research objectives. Most academic libraries are under considerable pressure from the teaching faculty to support their research interests. Those with limited financial resources have often neglected undergraduate needs. Because of this many libraries have developed mediocre and unbalanced collections. Libraries that cannot maintain strong basic collections should not undertake to develop specialized holdings. Because only a few institutions can aspire to strong research collections in all fields, acquisition of research material must normally be limited. Decisions about which areas to support and whether to build basic or comprehensive research collections should be based on the overall objectives of the university, graduate degree programs, requirements of institutes and research bureaus, as well as the specific interests of individual members of the teaching faculty and research workers. The library must define areas of emphasis within each discipline and restrict acquisition of research material to those fields. This insures the availability of sufficient material for research purposes although the range of subjects is limited.

3. Area resources. The existence and accessibility of comprehensive research collections can and should affect decisions regarding acquisitions programs. Funds should not be used to duplicate expensive or infrequently used resources that are already easily accessible.

Once needs have been evaluated and the appropriate level defined for each segment of the collection, the bibliographer must determine specific requirements for building or maintaining holdings at the desired level. This information is essential to any effective method for allocating funds. Identified or projected needs are the only valid criteria on which to base budgetary decisions. Three steps are involved in the process of defining needs: (1) determining the relative importance of monographic, serial, periodical and other material; (2) evaluating existing holdings for adequacy; and (3) selecting specific titles.

Ideally, all three steps can be accomplished at the same time by utilizing selective, authoritative bibliographies, which approximate the desired level of adequacy. By comparing the entries with existing holdings, the overall adequacy of the collection is established and specific deficiencies are identified. Frequently, however, there is no single bibliographic source which is suitable. In such cases, the bibliographer must rely either on a series of specialized bibliographies or on a comprehensive bibliography. Still other fields lack even these guides and the bibliographer must depend on a variety of other sources such as national bibliographies, book catalogs, accessions lists, citations, review media, bookseller's catalogs, or studies dealing with the literature of the field being evaluated.

The third step is to translate identified needs into specific dollar amounts, and to plan sufficiently far in advance to insure full consideration of financial requirements. In developing cost data, two , 
sets of figures are necessary: (1) a basic allocation; and (2) an augmentation. The basic allocation reflects the sum - necessary to support or maintain the collection at the desired level. This will include funds to purchase currently published material ${ }^{4}$ and to fill in minor gaps. Figures for current books are calculated on the basis of the anticipated rate of publication and the projected unit costs. Funds in this category will remain fairly stable from year to year, adjusted to changes in the rate of publication and cost, or to modifications in the scope of collecting. The augmentation is intend- ed to develop the collection to a level of adequacy by providing support for the purchase of titles identified in systematic bibliographic surveys. In most academic libraries, the level of adequacy is continually changing in response to a variety of factors, such as new degree programs, course offerings, faculty members, and research projects. Furthermore, increasingly detailed bibliographic research in each field will normally identify additional weaknesses. Cost estimates should reflect the percentage of titles that are in-print and out-of-print as well as the average price for each category. Often projects must be extended over a period of years owing to limited budgetary support, or because substantial amounts of the titles are outof-print and cannot be obtained during a single budgetary period. Therefore, while the basic allocation remains relatively stable, the augmentation fluctuates considerably from year to year.
Funds are allocated for specific purposes and, when one acquisitions program has been completed, funds can be diverted to other projects. Projects involving large amounts of out-of-print material are different in that a decreasing number of titles can be located in the antiquarian market with each successive year. In such cases, funds can be gradually reduced over a period of years.

In summary, allocating book funds should not be a control device, nor a matter of campus politics, nor the result of well intentioned but ill-informed judgments about the nature of library resources needed to support instructional programs. Nor is this simply a matter of objectivity as opposed to subjectivity, for complete objectivity in evaluating books and book needs is illusory. It is a matter of reducing as far as possible the degree of subjectivity that has traditionally influenced the allocation of book funds. For this reason, allocation should " be the result of academic and fiscal planning that expresses identified needs in terms of dollar costs. Assessments must be based on thorough bibliographic research and continual evaluation of the collection. While it is easy in theory to define such an approach, it is hard to do in practice. Yet the attempt is worthwhile. This approach alone forces the academic community-librarians, administrators, and teaching faculty alike -to approach the use of library funds in terms of what must be provided in order to support educational programs.

\section{REFERENCES}

1. Harry Bach, "Why Allocate?" Library Resources \& Technical Services 8:16165 (Spring 1964).

2. Charles J. Hitch, "Program Budgeting," Datamation 13:37-40 (Sept. 1967).

3. John D. Millett, Financing Higher Education in the United States (New York: Columbia Univ. Press, 1952), pp. 122-23; Herman H. Fussler, "Acquisition
Policy; A Symposium: The Larger University Library," College \& Research $\mathrm{Li}$ braries 14:364 (Oct. 1953).

4. In cases of libraries that have separate funds for new imprints, the basic allocation serves to maintain the retrospective collection and to purchase titles not identified during the current period. 